\title{
The Effect of Overt Prepositional Input on Students' Written Accuracy
}

\author{
Gareth Morgan \\ Centre for English Language Communication \\ National University of Singapore \\ 10 Architecture Drive \\ Singapore 117511 \\ E-mail: elcgm@nus.edu.sg
}

Doi:10.7575/aiac.alls.v.5n.5p.202

URL: http://dx.doi.org/10.7575/aiac.alls.v.5n.5p.202
Received: 07/08/2014

Accepted: 04/09/2014

\begin{abstract}
I believe that there should be a focus on problematic language issues such as prepositions in the language classroom in order to provide continuous exposure to such features. Consequently I provided my students with supplementary activities on prepositions, and also promoted learner autonomy by highlighting urls which deal with collocation. Analysis of the students written output shows the input to have been successful in focussing students' attention on this problematic language aspect. While a pre-input writing task generated 83 prepositional errors, at the rate of 1 in every 48 words, longer post-input tasks only generated 76 prepositional errors at the rate of 1 in every 215 words. Consequently, I plan to continue providing students with input on this often neglected language feature, in order to increase students' written accuracy.
\end{abstract}

Keywords: Prepositions, written accuracy, problematic grammatical issues, collocation, confusion, insertion, omission, peer interaction

\section{Introduction}

Research on the effects of English for Academic Purposes (EAP) courses on students' language skills have resulted in a number of contradictory conclusions being drawn. Some research has come to the conclusion that students make fewer errors post-input, while other research has come to the conclusion that students' accuracy has hardly improved after taking such a course. Consequently, research was undertaken to determine if the provision of explicit input on the often neglected topic of prepositions results in an improvement in students' use of this language feature.

\section{Focus}

Prepositions are words which show a connection. $O f$, for example, is a simple preposition comprising one word, while complex prepositions, such as because of, and in comparison with consist of either two or three words. They usually come after nouns, (or pronouns, noun phrases, gerunds or noun clauses beginning with a wh-word or how), adjectives and some verbs. While the standard position for a preposition is immediately before its object (She put the book in her bag), a preposition phrase, which is a preposition plus its object, can also begin sentences for emphasis (After Monday comes Tuesday). As well as this, there are cases where the object of a preposition is moved to the start of the sentence, with the preposition at the end (All tastes are catered for). It should also be noted that many adverbs have the same form as prepositions but are used differently because, unlike adverbs, prepositions have an object. Providing the students with the advice of Storch and Tapper (2009) aids them in determining which word class it is. This involves stating the word, followed by who or what. If the answer is a pro/noun, then the word is a preposition, as opposed to an adverb:

i) Travelling was easier before (preposition) the credit crunch.

ii) I hadn't been there before (adverb).

This language feature was chosen because focussing input on problematic grammatical issues is essential according to Richards and Reppen (2014), Fotos (1994), and Ellis (1995), amongst others, and prepositions are an aspect of the language which cause numerous issues for learners from various language backgrounds (Swan, 2001), including Singapore (Brown,1999). According to research conducted by Bitchener, Young and Cameron (2005) preposition errors comprised $29 \%$ of all the mistakes made by English language learners, while Chodorow, Gamon, and Tetreault's research revealed that out of 4550 sentences, $8 \%$ contained at least one preposition error (2010). In other research, Izumi, Uchimoto, Saiga, Supnithi, and Ishara (2003) discovered that the rates of preposition errors in a Japanese learners' corpus were 10\%, and in Felice and Pulman's work, $12 \%$ of all errors were related to the use of prepositions (2008). Furthermore, Deng, Lee, Lim, and Varaprasad, (2010) found that the percentage of 'collocation/idiom/preposition' errors was higher in a post-course test, compared to a pre-course test, increasing from $50.99 \%$ to $52.73 \%$. They are problematic to such an extent that work conducted by Tetreault and Chodorow (2008) discovered that the rating of prepositional use by two trained native speakers as correct or incorrect varied by $10 \%$ 
while marking non-native speakers' Test of English as a Foreign Language (TOEFL) essays, and, in completing a gapfill exercise of 200 sentences, there was $24 \%$ disagreement between them.

Prepositions can be problematic as they are numerous, and serve a variety of linguistic functions (Ototake \& Arake, 2009). They also share properties of lexical and functional categories, and are ambiguous in nature (Jurafsky \& Martin, 2008). For example, to has two functions, which are:

i) making infinitives: He needs to study.

ii) functioning as a preposition: He went to the library. In this case it is followed by a noun, as shown, or a gerund, such as: The population is accustomed to being exploited.

Despite it being widely acknowledged that the infinitival to derives from the preposition to, and has the characteristics of a preposition (Matzig, Druks, \& Craig, 2010), not all linguists agree that the infinitival to is, indeed, a preposition, with Mittwoch(1990) classifying it as a modal auxiliary. Consequently, for the purpose of this study, examples of the infinitival to being used incorrectly, have not been included in the analysis.

Moreover, prepositions can have a variety of meanings and/or functions depending on where and how they are used, such as behind which means at the back of, responsible for, and not as advanced or as successful. On top of this, the choice of a preposition for every context is dependent on the writer's intention (Islam \& Inkpen, 2010). They also share functional and lexical categories and the correct selection depends on the following noun, preceding verb, preceding noun, or a combination of the three (Chodorow, Gamon, \& Tetreault, 2010). Frequently, the collocation varies. For example, a discussion about something is possible, but not discuss about something. Moreover, different prepositions can have similar meanings even across nearly identical contexts, such as at night, in the morning and on Monday morning (Swan, 2005), and, a learner's mother tongue may also cause false friend errors. For example, at has 18 functions which correspond to different prepositions in other languages, according to Swan (2001), who also comments on the fact that in China, errors of all kinds are common, while even a language as close to English as Dutch has various prepositions for on (Pinker, 2007). Finally, as mentioned in the Introduction, despite there being some publications dedicated to this area, such as Platt (2001) and Sargeant (2002), this language feature tends to be ignored, or only taught superficially at certain levels in the literature (Boquist, 2009).

\section{The students}

The National University of Singapore's (NUS) undergraduate students, who do not possess the necessary English language qualifications upon enrolment, take a Qualifying English Test, which involves essay writing, to determine their language proficiency, with those failing to meet expectations, attending a compulsory Centre for English Language Communication (CELC) course, in order to improve their English language skills. The English for Academic Purposes (EAP) course in question focuses on undergraduate students' academic writing over 48 input hours spread over a semester of 12 weeks. The course's main aims included the development of language skills, and organizing and structuring essays, with an emphasis on grammatical accuracy, with one of the learner outcomes being the accurate application of grammar items in compound and complex sentences at the paragraph level. At the time of the research, most lessons were tutor-led instruction, with one-to-one consultations comprising a further 5 classes. As well as this there were grammatical rules presented on PowerPoint slides, together with authentic texts containing inserted errors which focussed on each grammatical area. These were provided for autonomous learning purposes, with the grammatical areas in question, being articles, run on sentences and comma splices, sentence fragments, connectors, nouns, parallel structures, pronouns, word forms, subject/verb agreement, modal verbs, and verb forms, as well as prepositions. There was also a series of Online Grammar Exercises, which formed $10 \%$ of the Continuous Assessment mark.

The 53 students taking part in the study were from China, Malaysia, Indonesia, and Vietnam, as well as Singapore, and were enrolled in the Faculties of Science, Engineering, and Arts and Social Sciences.

\section{Students' perceptions: Pre-course questionnaire}

At the beginning of the course, a Survey Monkey questionnaire (Appendix A) was used to ask students for their opinions on the English language. Of the 38 responses, 97\% believed grammatical knowledge to be either important, or very important for their studies and career:

\section{My exam questions are essay-based.}

Because I'm in the Arts faculty. Most of my work requires essay writing and articulation.

It is important as I am a CNM (Communications and New Media) major and I am required to write a lot such as press release.

I believe writing good reports and thesis for my future studies and careers are crucial, so grammar is important in conveying my idea across better.

I assume I will be writing reports and proposals in the future.

Some of the students broadened the importance of the language, relating it to life in Singapore in general: 
I believe it is important in every aspect of life

Proper and accurate communication is integral to our society

English is after all the universal language and the highly spoken one in Singapore too.

Only one student underplayed the importance of the language:

In the course of engineering, more emphasize is on our mathematics and scientific knowledge.

However, while 18\% believed their standard of English to be either good or very good, these respondents were outnumbered by their classmates who regarded their English to be poor or very poor, as $28 \%$ believed this to be the case, with the remaining 58\% regarding their language skills as being acceptable.

I did not invest enough of my time in grammar. Plus there are just so many rules!

Because I have been critized by everyone that I know on my grammar usage.

I do not know my verb, tenses well. Hence, I always have grammar mistakes in my writing.

I have trouble remembering and applying some grammar rules.

I am unclear about some of the basic use of grammar.

More pertinently, the respondents had least confidence when writing a formal essay or report. For this skill, only $37 \%$ felt confident compared to the $88 \%$ who felt confident when writing informal communication, such as emails.

Consequently, the majority of the students had motivation to work hard at improving their English language skills, providing a rationale for the input.

\section{Input}

Information was provided on the three types of errors, namely the use of a different preposition (confusion), not using a preposition when one should be used (omission) and using one when it should not be (insertion). Particular attention was paid to 'on' because along with 'of, to, in, for, with, at, by, and from', it comprises the nine most frequent prepositions in the British National Corpus (BNC) (Islam \& Inkpen, 2010), and, according to Jurafsky and Martin (2008), it is one of the seven most problematic prepositions, which, in descending order, are: of, in, for, to, with, on and at. To compound matters, it is overused in the Singapore context. This is partly explained by Brown's claim that it is "virtually always used when the meaning is "on the subject of", and, it is also added to transitive verbs, such as emphasize, as well as being used as a verb in its own right (1999). Therefore, this information was relayed to the students, along with authentic examples of their misuse (Appendix B).

According to Gardener (1983), cited in Scrivener (2005, p.64) there are seven different types of learner: linguistic, visual, musical, logical/mathematical, bodily/feeling (which I refer to as 'kinaesthetic'), interpersonal (contact with other people) and intrapersonal (understanding oneself), and he comments on the fact that everyone has these seven intelligences in different proportions. Consequently, I catered for the kinaesthetic learner with the activity depicted in Appendix $C$.

There was also a focus on the interpersonal learner. For example, the students were asked to complete questions with the correct prepositions, which were then used in a communicative activity with a classmate who had a different set (Appendix D), and in another activity, they decided with a partner whether a set of sentences contained the correct or incorrect preposition, correcting the erroneous ones (Appendix E). These were based on the aforementioned Brown (1999). Input was also personalized at the end of the course, as recommended by Richards and Reppen (2014), by turning examples from the students' writing into a worksheet similar to the one in Appendix E, with a focus on on due to the sheer volume of errors these prepositions caused over the duration of the course, such as:

I will place more emphasis in research in the future, and use the material into my essay

I evaluated on global warming.

The student-centred approach of peer interaction was the chosen formula, as well as attempting to strike a balance between theory and application because becoming proficient in a language, according to Cives-Enriques (2003) “...is the result of opportunities for meaningful interactions..." (p.253), while learners are more aware of their language after input, which is an integral part of acquisition (Fotos, 1994). For example, Storch and Tapper (2009) provided their students with explicit grammatical input, and analysed texts for language use. They also provided feedback on structure and language, with a discussion on common errors being followed by the provision of reformulations. In this research, prepositions were found to be the seventh most common type of error, pre-input with the 69 errors constituting 5.4\% of the total in the pre-input analysis. However, this fell to 50 errors, or $5.0 \%$ of the total, post-input, and in the qualitative data, one of the students specifically commented on the belief that there had been an improvement in his/her use of prepositions, as well as in general. 
Corder (1981, cited in Ellis, 2003), and Fotos (1994), found that a focus on grammar means learners becoming more aware in their communication, post-input, which is essential for language acquisition. Also, the most use, as well as the most complex use of the target language occurs during information exchange, which is why there was a focus on this type of activity. Moreover, Ellis (1995) claims that it is in the interest of learners to attempt to comprehend the "targeted structure in the input" (p.88) by "paying attention to linguistic features and meanings" (p.88), as this noticing results in language intake. Similarly, Lipnevich and Smith (2009) found that detailed feedback strongly correlated with improved essay scores as "Continued exposure to many examples of correct usage" is the best way to learn, while Ferris (2004), claims that "L2 student writers value error feedback from their teachers" (p.55), and believes that if it is not provided, fossilization may occur, preventing "longer term linguistic competence" (p.56).

This is in contrast to Shaw and Liu (1998), as mentioned in Storch and Tapper (2009), who discovered that no significant improvements in linguistic accuracy and complexity had been made by students after the completion of an EAP course. Similarly, Deng, Lee, Lim and Varaprasad (2010), came to the same conclusion with regard to their students' accuracy, despite $42 \%$ of the students themselves believing that they had made progress, having taken such a course, while Polio, Fleck, and Leder (1998) claim that students who receive error correction do not produce more accurate texts than those who receive no error feedback, and do not improve in accuracy over time.

As well as this, to promote learner autonomy, the students were encouraged to use the Oxford Advanced Learner's Dictionary in order to check collocations, as advocated by Storch and Tapper (2009), who also comment on the need to practice, pay attention and notice. It should be noted, however, that this has since been combined with the Oxford Advanced American Dictionary (OAAD) into one site: Oxford Learner's Dictionary. Finally, the use of Davies' website Word and Phrase. Info. (2014), was also encouraged.

\section{Post-course perceptions}

A post-course questionnaire (Appendix F) was completed by 18 students, who, generally speaking, provided positive feedback. $89 \%$ of the students felt that the right amount of grammatical input was provided, and, regarding perceived grammatical improvements made, the results are positive, as shown in Figure 1 below:

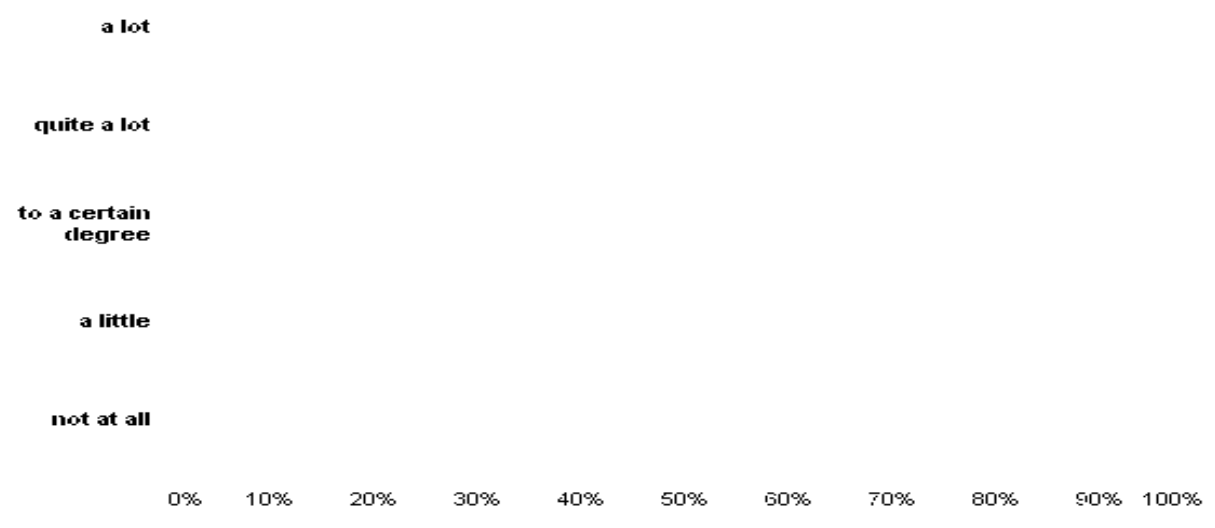

Figure 1. To what extent has your grammar improved?

The qualitative data reveals that of the students who responded positively, $28 \%$ claimed this to be due to an improvement being made in their use of prepositions, which was the highest percentage for any of the individual categories stated. On top of this, $21 \%$ claimed that their knowledge of phrasal verbs had improved, whilst generic statements were also made, such as:

I am more aware of the mistakes I make

Every aspect

Sentence composing

Such a high response for prepositions is unsurprising considering that with reference to the question on the grammar points covered, apart from verbs (tenses, forms and subject-verb agreement) at $40 \%$, prepositions had the highest recall rate among the respondents for a topic of input covered in class at $30.7 \%$, with a further $20 \%$ mentioning phrasal verbs. However, despite the input in this grammatical area, one student felt compelled to comment on the fact that the use of prepositions was an area which should have been covered, but wasn't (along with past participle and past perfect tenses, punctuation and use of connectors). As well as this, one reply was:

Cant really recall, many were covered. 
On a more negative note, one student felt compelled to write:

... it is not necessary to teach all the grammar points in classes. It is very boring. The slides and online assessments are enough.

\section{Data analysis}

\subsection{Pre-input data}

To begin with, data was generated by a writing task which was completed by 49 students in the first lesson. It involved the writing of a personalized paragraph, with the objective of the students introducing themselves to their peers and to the lecturer. The students could focus on any aspect of their lives they wished, in keeping with the humanistic approach which emphasizes the provision of choice, as well as personalization, as advocated by Tomlinson (2007). For this task, there was no word limit, and it wasn't assessed, which resulted in the length and the topics of the paragraphs varying greatly. The average length was 82 words, with the shortest being comprised of 33 words, and the longest of 204, which came to 4018 words. In total, 75 prepositions were used erroneously, at an average of 1.53 per student, which calculates as 1 error every 54 words, and these are listed in Table 1 below:

Table 1. Total Prepositional Errors Pre-Input: Introductory Paragraph

\begin{tabular}{|c|c|c|c|c|c|c|c|}
\hline \multicolumn{2}{|l|}{ INSERTION } & \multicolumn{2}{|l|}{ CONFUSION } & \multicolumn{2}{|l|}{ OMISSION } & \multicolumn{2}{|c|}{ COMBINED } \\
\hline to & 8 & in & 15 & in & 7 & in & 27 \\
\hline in & 5 & to & 6 & to & 6 & to & 20 \\
\hline for & 2 & of & 4 & about & 1 & of & 4 \\
\hline on & 1 & for & 3 & on & 1 & on & 5 \\
\hline around & 1 & on & 3 & & & for & 5 \\
\hline into & 1 & from & 2 & & & into & 3 \\
\hline with & 1 & into & 2 & & & with & 3 \\
\hline off & 1 & with & 2 & & & from & 2 \\
\hline & & as & 1 & & & about & 1 \\
\hline & & at & 1 & & & around & 1 \\
\hline & & up & 1 & & & as & 1 \\
\hline & & & & & & at & 1 \\
\hline & & & & & & off & 1 \\
\hline & & & & & & up & 1 \\
\hline TOTAL & 20 & & 40 & & 15 & & 75 \\
\hline
\end{tabular}

\subsection{Post-input analysis}

The post-input analysis was based on two sets of data. The first was a 700-800 word problem-solution essay, which contributed $\%$ of the students' overall grade. The process writing approach was the procedure undertaken for this task, with the first draft being analysed for the students' use of prepositions, before the provision of feedback. The topic was a serious consequence of globalisation the world is facing, and measures which can be implemented to alleviate this problem. 51 essays were analyzed in the process, all of which met the prescribed word limit, meaning the submission of at least 35,700 words.

To begin with, though the students' notes regarded the use of phrasal verbs as being inappropriate for essay writing due to their informal register, for the purpose of the research, I did not classify prepositional phrasal verbs as being erroneous when the correct verb plus preposition was used. Indeed, in the supplementary material, examples of phrasal verbs were included, such as point out in Appendix D. This language feature was focused on in the post-activity discussion. The students were advised that a one word verb equivalent should be used in academic writing, instead of a phrasal verb, whenever possible, due to the informal register of the latter. Also, when correcting an error could have been undertaken in more than one way, I suggested using a non-phrasal verb alternative, as opposed to the addition of a preposition. For example, with regard to:

\section{for everyone has the duty to look this problem}

I recommended changing the verb from look to research, as opposed to the addition of into. Neither were the previously mentioned examples of the infinitival to, included in the data analysis, nor incomprehensible prepositional phrases, such as:

\section{the crisis is lying under this candy-coat}

As shown in Table 2 below, the results are in contrast to those of Granger (1997), who concluded that the tendency was to underuse most prepositions. However, they correlate with the research conducted by Ahmad, Bukhari, and Hussain (2011) in which $71 \%$ of 201 errors were caused by confusion. 


\begin{tabular}{|c|c|c|c|c|c|c|c|}
\hline INSERTION & & CONFUSION & & OMISSION & & COMBII & \\
\hline for & 6 & to & 27 & of & 6 & to & 35 \\
\hline to & 5 & of & 16 & in & 4 & of & 26 \\
\hline on & 4 & in & 10 & on & 4 & on & 17 \\
\hline of & 4 & on & 9 & to & 3 & in & 16 \\
\hline in & 2 & with & 9 & from & 2 & for & 14 \\
\hline by & 2 & for & 7 & by & 1 & with & 10 \\
\hline as & 2 & from & 4 & for & 1 & from & 6 \\
\hline about & 1 & as & 2 & & & by & 5 \\
\hline into & 1 & at & 2 & & & as & 4 \\
\hline up & 1 & by & 2 & & & at & 2 \\
\hline \multirow[t]{7}{*}{ with } & 1 & along & 1 & & & into & 2 \\
\hline & & among & 1 & & & up & 2 \\
\hline & & into & 1 & & & about & 1 \\
\hline & & since & 1 & & & along & 1 \\
\hline & & towards & 1 & & & among & 1 \\
\hline & & up & 1 & & & since & 1 \\
\hline & & & & & & towards & 1 \\
\hline TOTAL & 29 & & 94 & & 21 & & 144 \\
\hline
\end{tabular}

The second set involved reflecting on experience, and in response to reading, with the students having analysed models of reflection on Gillett's website (2014). Again, there was a provision of choice, with the students reflecting on the most important "steps" on their English language learning journey, or, on why writing in English is important. This constituted $10 \%$ of the overall grade, with the errors generated shown in Table 3 below.

Table 3. Total Prepositional Errors Post-Input: Critical Reflection

\begin{tabular}{|c|c|c|c|c|c|c|c|}
\hline INSERTION & & CONFUSION & & OMISSION & & $\mathrm{COM}$ & \\
\hline on & 15 & in & 10 & on & 2 & on & 24 \\
\hline in & 4 & on & 7 & with & 2 & in & 14 \\
\hline of & 4 & into & 4 & about & 1 & of & 7 \\
\hline for & 3 & to & 4 & of & 1 & for & 6 \\
\hline about & 2 & at & 3 & to & 1 & to & 5 \\
\hline down & 2 & for & 3 & & & about & 4 \\
\hline \multirow[t]{6}{*}{ up } & 2 & from & 2 & & & into & 4 \\
\hline & & of & 2 & & & at & 3 \\
\hline & & about & 1 & & & down & 2 \\
\hline & & & & & & from & 2 \\
\hline & & & & & & up & 2 \\
\hline & & & & & & with & 2 \\
\hline
\end{tabular}

\section{Discussion}

While I agree with Storch and Tapper who claim that "To address all the potential difficulties ...would require volumes" (2009), I believe that there should be a focus on problematic language issues such as prepositions in the language classroom because, as commented on by Chodorow, Gamon, and Tetreault, "The best way to learn is through continued exposure to many examples" (2010), a belief supported by comparing the students' writing, pre- and postinput, as shown in Table 5.

Table 5. Use of prepositions pre- and post-input

\begin{tabular}{|c|c|c|c|c|}
\hline Task & $\begin{array}{l}\text { Pre- or post- } \\
\text { input }\end{array}$ & $\begin{array}{l}\text { Task } \\
\text { Length }\end{array}$ & $\begin{array}{l}\text { Number of } \\
\text { Errors }\end{array}$ & Ratio of errors \\
\hline $\begin{array}{l}\text { Introductory } \\
\text { paragraph }\end{array}$ & pre- & $\begin{array}{l}\text { not } \\
\text { stated }\end{array}$ & 75 & $1: 54^{*}$ \\
\hline Essay & post- & $700-800$ words & 144 & $1: 283 * *$ \\
\hline $\begin{array}{l}\text { Critical } \\
\text { Reflection }\end{array}$ & post- & $200-300$ words & 75 & $1: 217 * * *$ \\
\hline
\end{tabular}

As the supplementary activities on prepositions are shown in the data analysis to have been successful in focussing students' attention on this problematic aspect of the language, I plan to continue providing students with input in order 
to provide exposure to, and raise awareness of this often neglected language feature. Moreover, I am going to start using visual representation as advocated by Evans and Tyler (2005, cited in Boquist, 2009), to portray key differences in order to improve recall and reduce the memory work which must be invested in learning how prepositions are used, because of their sheer volume. I shall also encourage my students to read actively, paying attention to prepositional collocations in an academic context. This is especially important in Singapore given the sheer volume of erroneous authentic collocations the students are exposed to every day, as exemplified in Appendix B. However, due to it being unrealistic to expect nothing more than an improvement in the use of prepositions, as opposed to complete accuracy of usage, I shall also consider implementing software such as Criterion or ESL Assistant to complement the use of online dictionaries. This is software which Chodorow, Gamon and Tetreault (2010) have found be beneficial for written accuracy by highlighting prepositional errors and suggesting corrections. Furthermore, I will continue to personalize feedback by generating worksheets based on the students' erroneous output. While such an approach is in contrast to the stance advocated by Truscott (1996), who regards a focus on error correction as being ineffectual in increasing learners' written accuracy, it is an approach which is advocated by Ferris and Roberts (2001), for example, who are of the belief that it results in the production of more accurately written texts, and Chandler (2003), who found that it has the effect of improving accuracy in the long term. Finally, I shall also focus on verb patterns to attempt to minimize the number of errors made with regard to the use of to in infinitival forms.

\section{References}

Ahmad, N., Bukhari, M.A., \& Hussain, S. (2011). Error analysis: Learning articles and prepositions among secondary school students in Pakistan. Interdisciplinary Journal of Contemporary Research in Business, 2(12), 385-91.

Bitchener, J., Young, S., \& Cameron, D. (2005).The effect of different types of corrective feedback on ESL student writing. Journal of Second Language Writing, 14(3), 191-205.

Boquist, P.J. (2009). The second language acquisition of English prepositions. Liberty University Senior Honours Theses. Paper 99. Liberty University, Lynchburg, Virginia, USA.

Brown, A. (1999). Singapore English in a nutshell. Singapore: Federal Publications.

Chandler, J. (2003). The efficacy of various kinds of error feedback for improvement in the accuracy and fluency of L2 student writing. Journal of Second Language Writing, 12(3), 267-296.

Chodorow, M., Gamon, M., \& Tetreault, J. (2010). The utility of article and preposition error correction systems for English language learners: Feedback and assessment. Language Testing, 27(3), 419-346.

Cives-Enriques, R-M. (2003). Materials for adults: 'I am no good at languages!' - Inspiring and motivating L2 adult learners of beginner's Spanish. In B. Tomlinson. (Ed.), Developing materials for language teaching (pp. 239-255). London: Continuum.

Corder, S.P. (1981). Error analysis and interlanguage. Oxford: Oxford University Press.

Davies, M. (2014 ). Word and phrase. Info. Retrieved from: http://www.uefap.com/writing/genre/reflect.htm [Online], Available: 2014, [15 May].

Deng, X.D., Lee, K.C., Lim, M.L., \& Varaprasad, C. (2010). Academic writing development of ESL/EFL graduate students in NUS. In J. C. Richards (Guest Editor). Reflections on English language teaching (pp 119-138). Singapore: NUS Centre for English Language Communication.

Ellis, R. (1995). Interpretation tasks for grammar teaching. TESOL Quarterly, 29(1), 88.

Ellis, R. (2003). Task-based Language Learning and Teaching. Oxford: Oxford University Press.

Evans V. \& Tyler A. (2005). Applying cognitive linguistics to pedagogical grammar: The

English prepositions of verticality. Revista Brasileira de Linguistica Aplicada, 5(2), 11-42.

Felice, R.D., \& Pulman, S.G. (2008). A classifier-based approach to preposition and determiner error correction in L2 English. COLING '08 Proceedings of the $22^{\text {nd }}$ International Conference on Computational Linguistics, 1, $169-176$.

Ferris. D., \& Roberts, B. (2001). Error feedback in L2 writing classes: How explicit does it need to be? Journal of Second Language Writing, 10(3), 161-184.

Ferris, D.A. (2004). The "Grammar Correction” Debate in L2 Writing: Where are we, and where do we go from here? (and what do we do in the meantime...?). Journal of Second Language Writing, 13(1), 49-62.

Fotos, S.S. (1994). Integrating grammar instruction and communicative language use through grammar consciousnessraising tasks. TESOL Quarterly, 28(2), 323.

Gardner, H. (1983). Frames of mind: Theory of multiple intelligences. New York: Basic Books.

Gillet, A. (2014). Genres in academic writing. Using English for Academic Purposes: A Guide for Students in Higher Education. Retrieved from: http://www.uefap.com/writing/genre/reflect.htm [Online], Available: 2014, [15 May].

Granger, S. (1997). Learner English on computer. Harlow: Longman. 
Islam, A., \& Inkpen, D. (2010). An Unsupervised Approach to Preposition Error Correction. International Conference on Natural Language Processing and Knowledge Engineering (NLP-KE), 21-23 Aug. 2010, 1 - 4 [Online], Available at: http://ieeexplore.ieee.org.libproxy1.nus.edu.sg/stamp/stamp.jsp?tp=\&arnumber=5587782, 2014, [15 May].

Izumi, E., Uchimoto, K., Saiga, T., Supnithi, T., \& Ishara, H. (2003). Automatic error detection in the Japanese learner's English spoken data. Companion Volume to the Proceedings of the $41^{s t}$ Annual Meeting of the Association for Computational Linguistics (ACL), 145-148.

Jurafsky, D., \& Martin J.H., (2008). Speech and language processing. Upper Saddle River: Prentice-Hall.

Lipnevich, A., \& Smith, J. (2009). Effects of differential feedback on students' examination performance. Journal of Experimental Psychology: Applied, 15, 319-333.

Mätzig, S., Druks, J., Neeleman, J., \& Craig, G. (2010). Spared syntax and impaired spell-out: The case of prepositions. Journal of Neurolinguistics, 23(4), 354-82.

Mittwoch, A. (1990). On the distribution of bare infinitive complements in English. Journal of Linguistics, 26(1), 103131.

Ototake, H. \& Araki, K. (2009). Automatic preposition errors correction using inductive learning. 2009 World Congress on Computer Science and Information Engineering, 335-339.

Pinker, S. (2007). The stuff of thought: Language as a window into human nature. London: Penguin.

Polio, C., Fleck, C., \& Leder, N. (1998). 'If only I had more time': ESL learners' changes in linguistic accuracy on essay revisions. Journal of Second Language Writing, 7(1), 43-68.

Platt, J. (2001). Better ways with prepositions. Singapore: Federal Publications.

Richards, J.C. \& Reppen, R. (2014).Towards a pedagogy of grammar instruction. RELC Journal, 45(1), 5-25.

Sargeant, H. (2002). Understanding prepositions. Singapore: Learners Publishing.

Scrivener, J (2005) Learning teaching. London: Macmillan.

Shaw, P. \& Lieu, E.T-K. (1998). What develops in the development of second language writing. Applied Linguistics, $19,225-254$.

Storch, N., \& Tapper, J. (2009). The impact of an EAP course on postgraduate writing. Journal of English for Academic Purposes, 8, 207-223.

Swan, M., \& Smith, B. (2001). Learner English: A teacher's guide to interference and other problems. Cambridge: Cambridge University Press.

Swan, M. (2005). Practical English usage. Oxford, OUP.

Tetreault, J. \& Chodorow, M. (2008). Native judgements of non-native usage: Experiments in preposition error detection. COLING Workshop on Human Judgments in Computational Linguistics, Manchester.

Tomlinson, B. (2007). Connecting the course book. Essential Teacher, June, 2007. Retrieved from: http://www.tesol.org/read-and-publish/journals/other-serial-publications/compleat-links/compleat-links-volume-4-issue2-(june-2007)/connecting-the-course-book

Truscott, J. (1996). The case against grammar correction in L2 writing classes. Language Learning, 46, 327-369. 
Appendices

Appendix A

ES1102 Student Questionnaire \#1: This anonymous questionnaire should take about 10 minutes to complete. It will help me with my research, while reflecting should help you with your studies. Thank you very much for taking the time to complete it. January 2014

1. My knowledge of grammar:

$\mathbf{1}=$ very good $\quad \mathbf{2}$ = quite good $\quad 3$ = average $\quad 4$ =not good $\quad \mathbf{5}=$ poor

Why have you circled this number?

What are your particular strengths and/or weaknesses?

2. The importance of grammar for my studies and future career:

$\mathbf{1}=$ very important $\quad \mathbf{2}=$ quite important $\quad 3=$ neither important nor unimportant

$\mathbf{4}=$ not important $\quad \mathbf{5}=$ irrelevant

Why?

3. My knowledge of vocabulary:

$\mathbf{1}=$ very good $\quad \mathbf{2}$ = quite good $\quad 3$ = average $\quad 4=$ not good $\quad \mathbf{5}=$ poor

Why have you circled this number?

What are your particular strengths and/or weaknesses?

4. The importance of vocabulary for my studies and future career:

$\begin{array}{ll}\mathbf{1}=\text { very important } & \mathbf{2}=\text { quite important } \\ =\text { not important } & \mathbf{5}=\text { irrelevant }\end{array}$

Why?

\section{Appendix B}

Authentic Errors
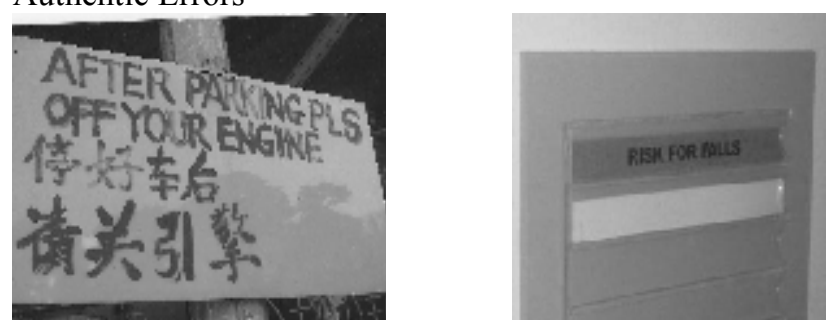

Can you find and correct the errors? 


\section{Appendix C}

A kinaesthetic activity on prepositions

Which preposition precedes the words I dictate? If the missing preposition is:

AT

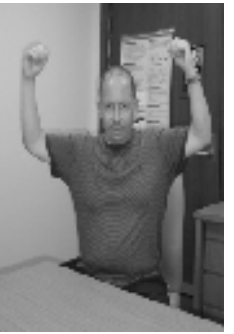

Raise your arms
ON

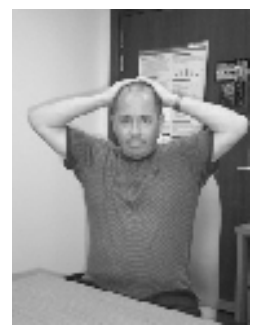

Put your hands on your head
IN

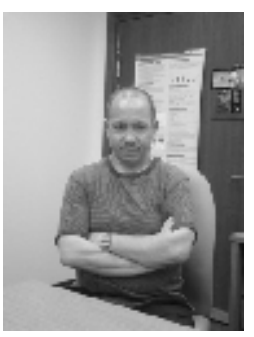

Fold your arms

For example, if you hear 7 o'clock, you should raise your arms.

\section{Appendix D \\ Problems with prepositions}

Student A: In your set of questions, either leave the space blank, or add a preposition. Then, ask the questions for your partner to answer, and to tell you if you have used the correct preposition. After that, answer your partner's questions, and tell him/her if s/he's used the correct preposition.

What are the reasons you being on this course?

Have you ever chaired a meeting?

Does your lifestyle cause damage

Is your future your own hands?

Have you ever been accused cheating?

Are you involved any voluntary work?

\section{Problems with prepositions}

Student B: Answer your partner's questions, and then tell him/her if s/he's used the correct preposition. With regard to your questions, either leave the space blank, or add a preposition, and then ask the questions. Your partner will answer and tell you if you have used the correct preposition.

Do exams add the pressure of being a student?

What did we discuss in the first session?

What nationalities is the class made up

Have you ever been told ___ the quality of your written work?

Could you list_all the names of the people here?

Are your writing skills proceeding a rapid speed?

\section{Appendix E}

\section{Common Prepositional Errors}

Are these sentences correct or incorrect? Correct the erroneous ones.

1. We shall discuss about overtime at the meeting.

2. University Hall is in campus.

3. Shall we participate a game?

4. If I'm ill, a colleague will deputize me.

5. How will you dispose of the rubbish?

6. I demand for more homework.

7. I regret for not doing my homework.

8. I have to stress the importance of getting prepositions correct in your correspondence.

9. Have I mentioned what we will do next week?

10. I look forward to see you next week.

11. Has anybody ever met with an accident?

12. Please lower the volume.

Errors can be categorized as follows: 


\section{Appendix F}

ES1102 Student Questionnaire \#2: This anonymous questionnaire should take about 10 minutes to complete. It will help me with my research, while reflecting should help you with your studies. Thank you very much for taking the time to complete it. April 2014. If there isn't enough space, feel free to continue writing overleaf

1. Grammatical improvements:

$$
\begin{aligned}
& \mathbf{1}=\text { a lot } \mathbf{2}=\text { quite a lot } \\
& \mathbf{5}=\text { not particularly } \quad \mathbf{3}=\text { to a certain degree }
\end{aligned}
$$

\section{Why have you circled this number?}

2. Improvements in vocabulary:

$\begin{array}{ll}\mathbf{1}=\text { a lot } & \mathbf{2}=\text { quite a lot } \quad \mathbf{3}=\text { to a certain degree } \\ \mathbf{4}=\text { not particularly } & \mathbf{5}=\text { not at all }\end{array}$

\section{Why have you circled this number?}

3. With regard to \#1 and \#2, which particular areas have improved, if any, and why?

4. The amount of input on grammar:

$\mathbf{1}=$ the correct amount $\quad \mathbf{2}=$ not enough $\quad \mathbf{3}=$ too much

5. The amount of input on vocabulary:

$\mathbf{1}=$ the correct amount $\quad \mathbf{2}=$ not enough $\quad \mathbf{3}=$ too much

6. Which areas which weren't covered with regard to grammar and/or vocabulary should be?

7. Which areas which were covered with regard to grammar and/or vocabulary shouldn't be? Why? 